\title{
Mapping Access to Affordable Early Childhood Education and Care: Methodology and Application to Community Advocacy
}

\author{
Javzandulam T. Azuma ${ }^{1}$ (D) Barbara D. DeBaryshe ${ }^{1}$ (D) Kathleen T. Gauci $^{1}$ (D) \\ Ivette Rodriguez Stern ${ }^{1}$
}

Received: 27 February 2020 / Accepted: 23 October 2020/Published online: 19 November 2020

(C) The Author(s) 2020

\begin{abstract}
Accessible and affordable early childhood care and education (ECE) is crucial to child, family, and community well-being. High quality ECE programs set the stage for lifelong learning, health, and overall well-being and yield a high rate of return on public investment. Equitable access to ECE remains an intractable challenge in the U.S. and elsewhere. We used spatial analysis to create a single micro-level indicator of ECE affordability for an urban county. This indicator combined information on supply (number of nearby sets), demand (number of children competing for these seats), and cost burden (cost as a percentage of median family income). We measured and mapped the affordability of programs within a 3-mile driving distance of a prototypical family home using a two-step floating catchment area method. Overall, affordability was low, with only $14 \%$ of young children having access to ECE that met the federal affordability threshold. Although affordability was inversely related to neighborhood income, not all low-income areas were under-resourced. The ECE affordability indicator can arm community advocates and help policymakers identify inequities and direct resources to the highest-need communities. The computational procedures and mapping techniques applied are flexible and can be scaled up to visualize inequities across large areas (e.g., a province or state), or used at a micro level to identify where in a community a new childcare center would have the most impact.
\end{abstract}

Keywords Community well-being · Community indicators · Childcare · Early childhood . Equity $\cdot$ Mapping $\cdot$ Spatial analysis

Javzandulam T. Azuma

javzan@ hawaii.edu

1 Center on the Family, University of Hawai'i at Mānoa, Honolulu, HI, USA 


\section{Introduction}

Access to affordable, conveniently located, and high quality early childhood care and education (ECE) programs is crucial to the well-being of children, families, and communities. Equitable access exists when all families "with reasonable effort and affordability, can enroll their child in an arrangement that supports the child's development and meets the parents' needs" (Friese Lin et al. 2017, p. 5). While ECE policy is usually set at a national or regional level, variation in access is often experienced at the community level. Measures of access are useful for identifying communities with unmet needs, planning for the strategic expansion of services, and tracking the outcomes of policies intended to increase the availability and use of ECE programs.

The early childhood period (birth through age 5) is a period of exquisite sensitivity to environmental influences when positive caretaking relationships and enriching daily experiences set the stage for lifelong learning, health, and well-being (National Scientific Council on the Developing Child 2007). Young children spend a considerable portion of their time in ECE settings, and the widespread and lasting consequences of such care is well documented. High-quality ECE programs support children's physical health, language and cognitive skills, and social-emotional development (Gormley et al. 2008; Phillips et al. 2017; Yoshikawa et al. 2016). Furthermore, such programs partially offset the negative impacts of poverty and other risk factors on early school success (Barnett 2011; Magnuson et al. 2004; Phillips et al. 2017). ECE participation is associated with lower rates of grade retention and special education placement in middle school; increased high school graduation rates, achievement test scores, and college enrolment; and higher earnings, better health, reduced substance use, and less criminal activity in adulthood (Barnett 2011; Yoshikawa et al. 2016).

Reliable, affordable childcare allows parents to work or attend school, thus building financial and human capital. Childcare promotes gender equity by supporting women's labor force participation, better pay, and career advancement (European Commission 2014; Kawabata 2015; Morrissey 2017; OECD 2019). The worforce participation of single and low-income mothers is especially sensitive to variation in ECE supply, cost, and subsidies (Malik 2018; Mathur and McCloskey 2014). In the U.S., 65\% of children under age 6 need care because their parent(s) work (Bureau of Labor Statistics, 2019). Across the countries tracked by the Organisation for Economic Co-operation and Development (OECD), 53\% of mothers with children age $0-2$ and $67 \%$ of those with children age 3-5 are employed (OECD n.d.a).

Childcare is also a major family expense. In the U.S., the average ECE tuition for a single child represents $11 \%$ of the median income of two-parent households, $37 \%$ for single parents, and over $60 \%$ of the annual full-time federal minimum wage (Child Care Aware of America 2018). Across OECD nations, many of which offer generous childcare supports, the average out-of-pocket cost for a family with two young children is still 8-10\% of net income (range $0 \%$ to 37\%) (OECD n.d.b). Challenges that parents report in accessing childcare include cost (59\%), the availability ot seats (58\%), physical access such as distance or hours of operation (41\%), and lack of quality programs (27\%) (Eurofound 2012).

ECE access is also an issue for employers. Work-family conflict and childcare breakdowns affect worker productivity, attendance and turnover (Belfield 2018; Glass and Estes 1997), resulting in an estimated \$57 billion per year in lost wages, employer expenses, and unrealized tax revenue (Belfield 2018). Family-friendly policies such as 
onsite childcare, childcare vouchers and childcare savings accounts are associated with higher employee job satisfaction, productivity, and loyalty; reduced absenteeism and turnover; and serve as an effective recruitment tool (Anderson and Geldenhuys 2011; Bright Horizons Family Solutions 2013; Friedman 2001; Lauber and Storck 2016). Providing childcare benefits can result in cost-savings to companies and have sometimes been associated with higher profits, stock values, and organizational performance (Gammage et al. 2019; Lee and Hong 2011; Shellenback 2004).

Better outcomes for children, families, and employers translate into cost savings for society. Economists estimate that each dollar spent on early childhood programs yields a return to society of $\$ 2.00$ to $\$ 8.60$ due to increased family earnings and retirement accumulations, children's future earning potential, employer savings, and reduced need for remedial education, health care, and social services (Council of Economic Advisors 2015; Karoly 2016; Phillips et al. 2017; The Front Project 2019). Since high employment rates are an important component of economic prosperity, childcare contributes to overall economic well-being by supporting widespread workforce participation (OECD 2019).

Given the clear public benefits of ECE, sound policy would dictate that parents have access to an adequate supply of affordable programs, with equitable access across communities, ethnic, and socioeconomic groups. Across the OECD countries, $32 \%$ of infants and toddlers, $77 \%$ of three-year-olds, and $89 \%$ of four-year-olds are enrolled in some form of ECE, either full- or part-time (OECD n.d.c). However, even in counties with high enrollment, access is not always equitable. In many countries, regional enrollment rates vary by $20 \%$ or more (OECD 2019). In Canada, it is estimated that $44 \%$ of young children live in childcare deserts, defined as areas with more than three children in the resident population for each licensed childcare seat (Macdonald 2018). In the U.S., $51 \%$ of communities (i.e., census tracts) are childcare desserts, with access varying widely across states and as a function of urban, suburban, and rural locale and ethnic minority population (Malik et al. 2018).

Programs intended to reduce economic inequity by providing free or low-cost ECE often have insufficient reach. In the U.S., one out of four children of low-wage workers are eligible for federal childcare subsidies, but only $15 \%$ of these eligible children actually receive such benefits (Chien 2019). Head Start and Early Head Start, no-cost programs for children living in poverty serve $43 \%$ and $5 \%$ of eligible children, respectively, and enrollment varies as a function of ethnicity and race (Schmit and Walker 2016). In general, access, affordability, and choice are limited for poor families, minority and single parents, those who work non-traditional hours, and families in rural or economically distressed areas (Forry et al. 2013; Malik et al. 2018).

Policymakers and key stakeholders need accurate and timely community-level indicator data in order to define baseline conditions, set target goals, and track changes in conditions over time. The use of statistical data and indicators to measure and monitor various aspects of child well-being dates back to the 1970s. These early efforts focused on synthesizing existing administrative data (e.g., infant and child mortality rates, immunization rates, school enrollment) to describe the status of children in a given region or area, typically addressing their basic survival needs (Ben-Arieh 2008; Lippman 2006). The child indicator field has evolved over the decades. Key factors contributing to this evolution include (a) a children's rights perspective and new theories of childhood and child development, (b) a shift to look beyond child survival to child well-being and positive outcomes, and (c) a call for more policy-oriented research (Ben-Arieh 2008, 2010). Additionally, the field became creative in 
its use of administrative data sets for the purpose of monitoring child well-being and the variety of large scale data sources grew (e.g. the National Survey of Children's Health). Child indicators projects have now developed beyond the use of a comprehensive set of indicators to the creation of indices that track and compare conditions and outcomes within and across geographic regions, with such efforts playing an increasingly important roles in planning and governance (Ben-Arieh 2008, 2010; Lippman 2006). For example, U.S. researchers have developed a Child Opportunity Index combining 29 indicators of neighborhood characterstics that support child health and well-being (Acevedo-Garcia et al. 2020). The European Union recognizes universal access to affordable and high-quality childcare as a right and to this end, established a conceptual framework, benchmarks, and data reporting systems for monitoring progress across 38 European countries (European Commission/EACEA/Eurydice 2019). One stated purpose of providing these periodic comparative data is to support policy development and academic research.

When equity is an issue, the identification of high-need communities allows resources to be allocated to the most under-served areas. To more accurately understand the intricacies of ECE accessibility, spatial analysis can be used to provide area-based visualizations of trends and patterns. Spatial analysis is widely used in public health (Pfeiffer et al. 2008; Rushton 2003). For example, Hanna-Attisha, LaChance, Sadler, and Schnepp (2016) used spatial analysis to identify neighborhoods where children had elevated blood lead levels associated with the Flint drinking water crisis; this analysis helped to identify areas of highest risk and guide municipal and nongovernmental relief efforts. Spatial analysis has recently been added to the ECE policy analysis toolkit and shows much promise for advancing the field (Lin and Madill 2019). Using these methods, Sandstrom et al. (2018) identified census tracts that were childcare deserts for low-income families and estimated the number of new, subsidized seats needed to meet demand. Another policy research team identified clusters of neighborhoods representing areas of concentrated disadvantage and explored the density and funding source of high-quality preschool programs in these areas (Acevedo-Garcia et al. 2011).

The purpose of this paper is to present a methodology for measuring and visualizing ECE access at a micro level. Specifically, we developed a spatially-based measure of ECE affordability that combines information about the number of ECE seats located within a reasonable distance to the family's home, competition for these seats, and the cost burden to parents to purchase these ECE services. By incorporating information about individual family residences, this "family-centered" approach (Davis et al. 2019; Friese et al. 2017) reflects the everyday, practical reality of family life. Because the measure is spatially-based, it can be mapped to show how neighborhoods vary on a continuum from low to high accessibility. The metric may also be used in traditional statistical analyses to address issues such as change over time and the association between access and other community characteristics.

Most often, affordability is measured as the average cost of licensed ECE seats in a defined geographic region such as state, county, municipality, or postal code. The average cost is easy to compute and understand but has several limitations. First, the cost is not considered in relation to a family's income or ability to pay. A monthly fee of $\$ 800$ may be easily affordable for a wealthy family but simply impossible for a low-income household. Second, supply and demand are not taken into account: When supply is low relative to the number of children potentially competing for a seat, families have less flexibility to select a lower-cost seat and may not be able to find an empty seat at any cost. Thus, the cost of seats should be 
weighted by the number available at different price points, and the ratio of seats to the number of young children needing ECE services should also be considered. Third, metrics based on static geographic boundaries ignore the reality that families can and do travel to ECE sites outside their neighborhood, district or county, thus crossing these abstract area boundaries. The static boundary method also assumes that all EC facilities within the target area are equally accessible. This is unlikely to be the case, especially when the target area is relatively large. For example, families may prefer to enroll their children in facilities closer to home, or programs may be clustered in the more densely populated sections of a county.

The two-stage floating catchment area (2SFCA) method is a solution to the limitations of static area boundaries. The 2SFCA approach has been used to measure access to resources such as health care providers (Guagliardo 2004; Luo and Wang 2003) and green space ( $\mathrm{Li}$ et al. 2016): These methods have only recently been applied to the study of ECE access (Davis et al. 2019; Kawabata 2015; Lin and Madill 2019). As applied to the example of ECE access, the first step of the 2SFCA approach is to calculate for each ECE provider the ratio of seats offered to the number of children living within a set distance i.e., catchment area, of that provider. The second step is to sum these ratios for all providers within a set distance of each potential family consumer. The result is a single score for each family that captures multiple sources of information.

In this study, we used a single urban county to illustrate the usefulness of the 2SFCA method. We created a micro-level index of ECE affordability that combines data on program capacity, competition for seats, cost, family income, and location. Because our interest is the experience of typical families, we computed and analyzed the affordability index at the level of individual residential lots. We visualized the index using GIS mapping and performed hotspot analysis to identify areas with high, average, and low ECE affordability. Finally, we evaluated equity in access by testing whether affordability for families was systematically associated with the characteristics of the neighborhood in which they live. In addition to answering questions about the equitable distribution of ECE affordability across neighborhoods, our study illustrates how spatial analyses and visualization may be used to answer a variety of policy-relevant questions about community access to this needed resource.

\section{Method}

\section{Study Setting and Context}

The U.S. state of Hawai' $\mathrm{i}$ is located in the Pacific ocean and consists of an archipelago of over 130 islands, six of which are considered to be the main inhabited islands. Our analyses focus on the City and County of Honolulu, which comprises the land mass of

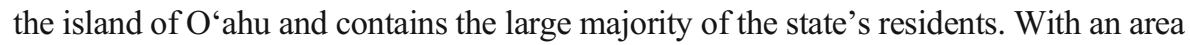
of 5967 mile $^{2}$ and a residential population of 986,999 (U.S. Census 2017a), O'ahu includes urban, suburban, and rural areas and is characterized by high ethnic diversity.

The U.S. follows a market-based model for ECE. There is no universal right to ECE placement nor is attendance compulsory. Nationwide, about one-half of four-year-olds are enrolled in publically-funded preK programs (Friedman-Krauss et al. 2020) and subsidies offset the cost of private childcare for some low-income families. However, eligibility criteria and enrollment vary widely across states. In Hawai‘i, only $13 \%$ of 
four-year-olds and $10 \%$ of four-year-olds attend no-cost, publically-funded programs (Friedman et al. 2020). Capacity is a concern for Hawai' $i$ - the state has enough licensed childcare seats to serve about one in four preschool age-children and only one in 37 infants and toddlers (DeBaryshe et al. 2017). No systematic data are kept on the use of informal childcare arrangements.

\section{Data Sources and Measures}

\section{Provider cost and location}

Childcare licensing and market survey data were provided by the statewide childcare resource and referral agency (CCRRA). These data were current as of May 2016. Variables used from this dataset were license type, licensed capacity, fees charged, and location. ECE providers included in this study were infant-toddler (IT) centers serving children up to age 3 and preschool centers serving children age 2-5. Public preschool and special education classrooms, as well as military childcare centers, were not included as these programs are license-exempt in Hawai'i. Family childcare providers were also excluded. Provider addresses were geocoded to the street level and assigned longitude and latitude coordinates. Costs were converted from monthly to annual full-time equivalents. For centers with an age-based fee scale, fees were averaged across age groups.

Figure 1 shows the location of providers along with capacity and tuition information. ${ }^{1}$ There were 326 licensed centers and 14,940 total seats. Over $37 \%$ of the providers were in the urban core with few providers located in rural O'ahu. The mean monthly tuition was $\$ 900$ (range $\$ 400$ to $\$ 2150$ ).

\section{Residential Location}

Residential property information for Honolulu County was extracted from a publicly available real property database and commercially available property data (SmartParcels 2017). The database includes whether each lot is residential or not, and the number of housing units on that lot. In total, there were over 150,000 residential lots, including 280,000 housings units (e.g., single-family homes, discreet apartments inside a duplex or apartment building). These data were used to approximate the spatial distribution of young children's residences.

\section{Early Childhood Population}

Five-year population estimates for children under age 6 were obtained from the American Community Survey (ACS) (U.S. Census Bureau 2017b). We excluded children who lived on military bases because data for on-base ECE facilities were not publicly available, resulting in an estimated 65,065 children under age 6 .

We used the census block group, as this was the smallest geographic unit for which these data were available. We assumed that every residential lot housed young children and that children were distributed to residential lots within a census block group in

\footnotetext{
${ }^{1}$ Circle sizes are proportional to the provider's licensed capacity. The graduated color represents the provider's tuition.
} 


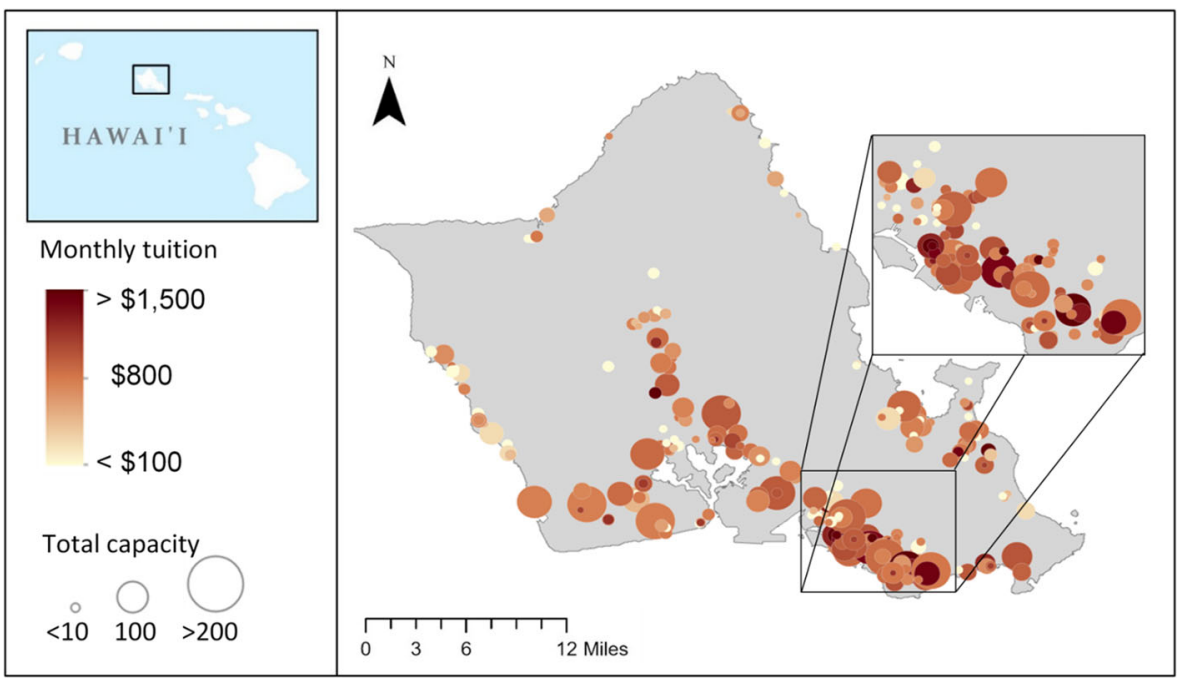

Fig. 1 ECE provider location, cost, and capacity

proportion to the number of housing units at each lot. The number of children under age $6\left(P_{i}\right)$ per residential lot $i$ was approximated as follows:

$$
P_{i}=\frac{H_{i}}{H_{b}} P_{b}
$$

where $P_{b}$ is the number of children under age 6 within the census block group $b, H_{i}$ is the number of residential units at the lot, and $H_{b}$ is the number of residential units within the census block group $b$.

\section{Family Income}

Because no data source for family-level income exists, we used five-year estimates from the ACS as a proxy measure. Income specific to families with young children are not reported, so we used the median income of families with children under age 18 at the census tract level (U.S. Census Bureau 2017c). The county-level median family income was US $\$ 83,399$, with considerable differences across census tracts (range $\$ 13,359$ to $\$ 203,750$ per year).

\section{Creating an Affordability Index}

The 2SFCA method was used to calculate the ECE affordability index for each residential lot. This index incorporated spatial accessibility (nearby seats), density (seats per capita), and cost burden (cost as a percentage of median family income). The 2SFCA method measures accessibility in two steps by considering both demand and supply. The first step assesses availability as supply-to-demand ratios in user-defined catchment areas, which are centered at the providers' locations. The second step sums the ratios in the overlapping catchment areas where residents have access to multiple provider locations. First, we delineated a catchment area showing all residential lots within a 3-mile driving distance of each ECE provider. This 3-mile distance was selected based on national averages that low-income 
families travel to access childcare (National Survey of Early Care and Education Project Team 2016). The optimal driving route from each ECE provider to nearby residential lots was computed using the Network Analyst in ArcGIS Pro. We then calculated the index using the steps outlined below. Detailed calculations are presented below.

Step 1. For each provider $j$, we calculated the capacity-to-population ratio $R_{j}$ by summing the number of children under age 6 at each lot within the $D$-mile catchment area from provider $j$ :

$$
R_{j}=\frac{C_{j}}{\sum_{i \in U_{j}} P_{i}}
$$

where $C_{j}$ is the capacity of provider $j, P_{i}$ is the number of children under age 6 at residential lot $i$, and $U_{j}=\{i: d(i, j) \leq D\}$ is a set of residential lots $(i)$ that are in the $D$-mile catchment area centered at a given provider $j$. For our purposes, $D$ was defined as 3 miles.

Step 2a. For each lot location $i$, we calculated the childcare cost $S_{i}$ as the availabilityweighted average tuition fees of nearby providers:

$$
S_{i}=\sum_{j \in U_{i}} \frac{E_{j} * R_{j}}{\sum_{j \in U_{i}} R_{j}}
$$

where $E_{j}$ is the annual tuition of provider $j$, and $R_{j}$ is the capacity-to-population ratio within the D-mile catchment area centered at provider $j$, and $U_{i}=\{j: d(i, j) \leq D\}$ is a set of providers $j$ that are within the $D$-mile catchment area.

Step $2 \mathrm{~b}$. For each lot location $i$, affordability index $F_{i}$ is computed as the ratio of the availability-weighted average of the tuition $S_{i}$ to the annual median income of families at lot $i$ :

$$
F_{i}=\frac{S_{i}}{I_{t}} \times 100
$$

where $I_{t}$ is the median income of families with children for lot $i$, (as estimated by the census tract median income). This index returns a value for each residential lot, indicating on average the percentage of the area's median family income needed to pay for a seat in programs where their child is most likely to be enrolled. Higher values indicate less affordable ECE services.

\section{Hot-Spot Analysis}

We were also interested in identifying clusters of residential lots with significantly high and low affordability. We calculated Getis-Ord Gi* using ArcGIS pro, Spatial Statistics Tool with first-order polygon contiguity edges. The Gi* statistic returns a z-score and $p$ value for each residential lot, indicating the extent to which the affordability index in the focal and neighboring lots deviate significantly from the mean affordability index of the county. Higher positive $\mathrm{Gi}^{*} \mathrm{Z}$ scores indicate higher affordability segregation. Scores near 0 indicate average affordability, and lower negative scores suggest lower affordability in comparison to the county overall. 


\section{Investigating Disparities in Affordability across Income Levels}

Our final interest was to investigate disparities by testing whether affordability varied systematically as a function of family income. We created an ordinal-level income variable to classify lots into a manageable number of income groups. To do this, we calculated the relative income ratio $R I$ for each residential lot defined as family income divided by median county income. Following the definitions of the Code of Federal Regulations (Community Reinvestment Act (Regulation BB) 2002), we classified each residential lot as upper-income $(R I \geq 1.2)$; middle-income $(0.8 \leq R I<1.2)$; moderateincome $(R I<0.8)$; or low-income $(R I<0.5)$. Affordability for the different income level groups was compared using a one-way analysis of variance.

\section{Results}

\section{Affordability}

The mean affordability index was 9.7 (median 8.6, SD 3.8, range 1.0 to 63.3), indicating that a typical family would pay $9.7 \%$ of their income to purchase ECE services close to their home. The U.S. federal government defines affordability for lowincome families as spending no more than 7\% of household income in total on ECE for all children in the home (U.S. Department of Health and Human Services, Office of Child Care 2016). Thus, an index score of 7 or lower is considered affordable.

To simplify visualization and interpretation, index scores were divided into five groups, ranging from 5 or less to over 16 (see Fig. 2). Higher index values indicate less affordable ECE. Lots indicated in the two darkest shades of blue (index scores of 7 or less) represent residences with nearby access to affordable ECE, while the other shades of blue and gray represent lots with access to less affordable ECE. The orange shade represents unserved lot with no ECE providers within a 3-mile driving distance. ${ }^{2,3}$

The percentage of residential lots at the different levels of the affordability index is shown in Table 1. Overall, affordability was low, with $71.8 \%$ of lots in areas where ECE cost per child was more than $7 \%$ of the neighborhood median income (sum of the last three columns). Furthermore, 9.3\% of lots had no access to ECE within a 3-mile driving distance.

\section{Hotspot Analysis}

The hot spot analysis identified clusters of residential lots with significantly high and low affordability (see Fig. 3). Blue areas in the figures represent cold spots, where the affordability index, or cost burden, is significantly lower than the county average at the $p<.05$ level. Grey areas represent lot clusters where affordability is similar to the county average, and red areas signify residential clusters where the affordability index, or cost burden, is significantly higher than average $(p<.05)$. Residential lots with no

\footnotetext{
${ }^{2}$ White areas on the maps indicate non-residential zones, e.g., commercial and industrial lots, agricultural land, airports, military bases, and conservation land. Much of the interior of the island consists of mountainous watershed zones with few or no public roads.

${ }^{3}$ For an example using these same data aggregated at a less granular level, i.e., census tract, see https://drive. google.com/file/d/1_xMLMoWIfz4yEayP_MEtlmUFNv-qU1IM/view?usp=sharing
} 


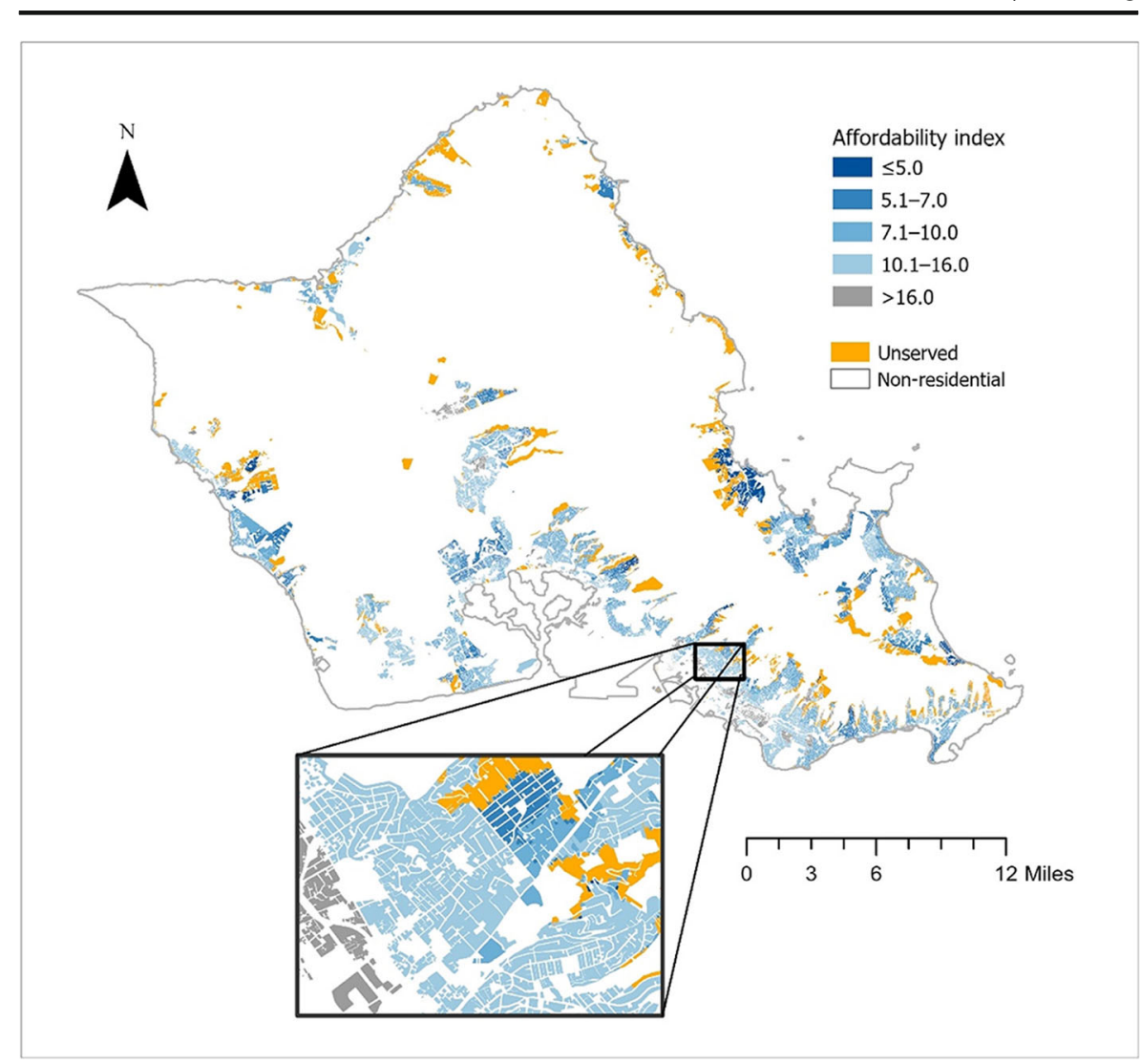

Fig. 2 Affordability index of ECE within a 3-mile driving distance of each residential lot

ECE providers within a 3-mile driving distance were excluded from the hotspot analysis.

As expected, the hot spot analysis map (Fig. 3) has many similarities to the lot-level affordability index map (Fig. 2). Neighborhoods along the southeastern and southwestern coast and in central $\mathrm{O}^{\prime}$ ahu had the least affordable ECE programs, relative to family income. Neighborhoods in east Honolulu and inland mountainous areas had the most affordable care; these tended to be high-income neighborhoods. However, affordability and neighborhood income were not synonymous. Some low-income neighborhoods

Table 1 Number and percentage of residential lots by affordability index

\begin{tabular}{|c|c|c|c|c|c|c|}
\hline \multirow[b]{3}{*}{ Lots } & \multirow[b]{3}{*}{ Unserved } & \multicolumn{5}{|c|}{ Affordability Index Range } \\
\hline & & \multicolumn{2}{|c|}{ High Affordability } & \multirow{2}{*}{$\begin{array}{l}\text { to } \\
7.1-10.0\end{array}$} & \multicolumn{2}{|c|}{ Low Affordability } \\
\hline & & $\leq 5.0$ & $5.1-7.0$ & & $10.1-16.0$ & $>16.0$ \\
\hline Number Percentage & $13,4479.3 \%$ & $44763.1 \%$ & $23,06915.9 \%$ & $57,12539.3 \%$ & $38,84826.8 \%$ & $82415.7 \%$ \\
\hline
\end{tabular}

Note. Affordabilty is the capacity-weighted average cost of an ECE seat as a percentage of the median family income in the census tract where the residential lot is located. High index scores are less affordable because a larger percentage of income is needed to pay for a childcare seat 


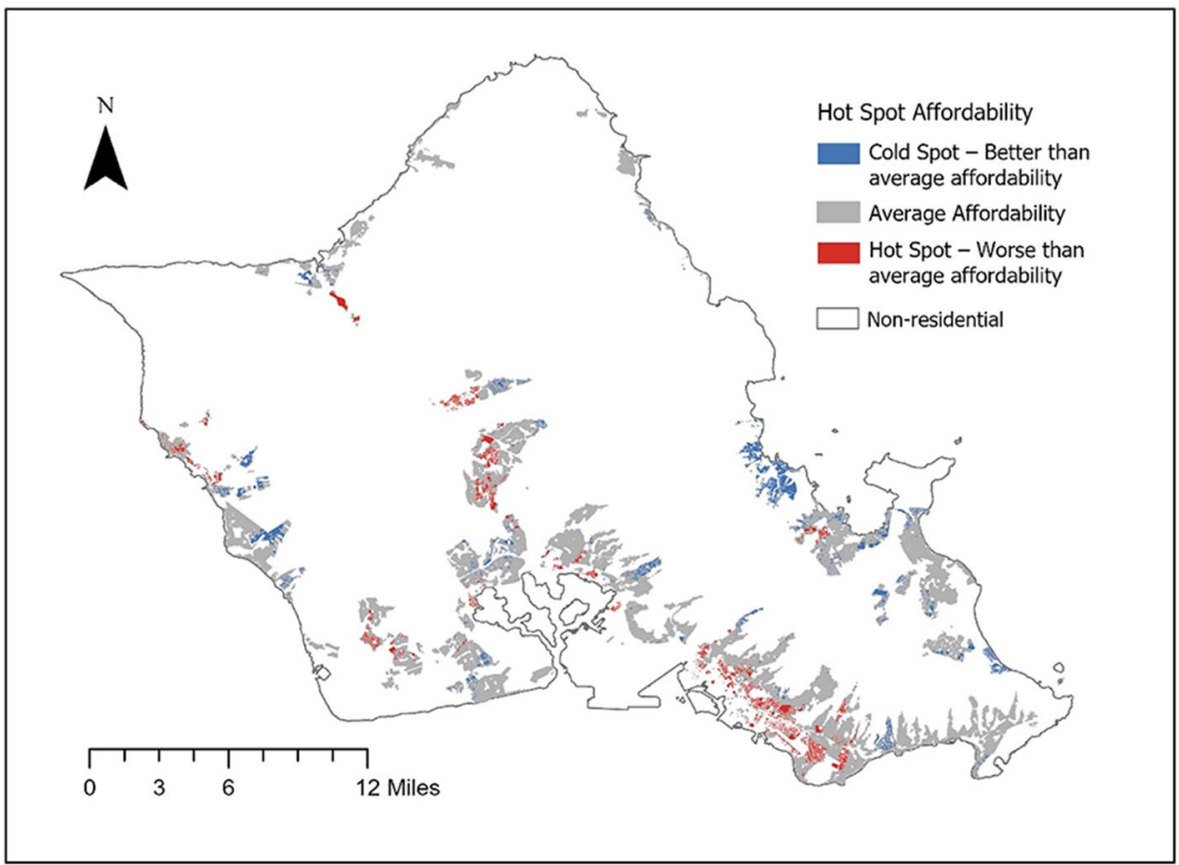

Fig. 3 Hot spot analysis: Clusters of residential lots that differ significantly on ECE affordability

had average levels of affordability, likely because they were well served by no-cost ECE programs run by Head Start and Native Hawaiian serving organizations. In analyses not reported here, hot spots were not associated with population density. However, cold spots had significantly lower population density than average, indicating that childcare was more affordable in rural neighborhoods.

\section{Analysis of Disparities in Affordability across Income Levels}

We conducted a one-way analysis of variance to test for a systematic association between neighborhood income level and ECE affordability. The four-level independent variable was the income level of the census tract in which each lot was located and the dependent variable was the affordability index score for each lot. The results are shown in Table 2. There was a strong effect for income level, with wealthier areas having relatively more affordable care, $F=24,930.1, d f=3,131,755, p<.0001$. Post hoc tests indicated that each group mean was significantly different from all other means.

\section{Child-Level Analysis}

Although our measures focused on the residential lot as the unit of analysis, for policy purposes, a focus on the number of children would be more easily interpreted. We estimated the total number of children based on the expected distribution of children per housing unit and the number of units per residential lot. The descriptive results are shown in Table 3. 
Table 2 Means and standard deviations for affordability index as a function of neighborhood income level

\begin{tabular}{lllr}
\hline Income Level & $n$ & Mean & $S D$ \\
\hline High & 68,268 & 8.0 & 1.7 \\
Middle & 44,939 & 10.2 & 3.3 \\
Moderate & 15,519 & 13.9 & 5.4 \\
Low & 3033 & 18.3 & 6.2 \\
\hline
\end{tabular}

Note. Income levels for census tracts based on $R I$ score

As shown in the bottom row of Table 3 , slightly more than $14 \%$ of all children lived in areas with access to nearby, affordable ECE services, i.e., index scores of 7 or less. The plurality, $62.3 \%$, lived in areas with an affordability index of more than 7 but less than 16.1 , and $15 \%$ of children lived in areas where ECE costs exceeded $16 \%$ of the median area family income. In addition, $9.3 \%$ of children did not have access to nearby programs. Across income strata, differences in affordability were striking. For example, almost no children in high and middle-income neighborhoods had area average affordability index scores above 16 . In contrast, this was the case for more than half of children in moderate and low-income neighborhoods. Children in low-income neighborhoods were also the most likely to lack access to any nearby ECE centers.

\section{Discussion}

Access to conveniently located, affordable ECE programs is an important component of community well-being, especially when support for young children's healthy development and the needs of working parents are considered. We presented a new method for measuring and visualizing this social indicator in a way that

Table 3 Estimated number and percentages of children by neighborhood income level and affordability index

\begin{tabular}{|c|c|c|c|c|c|c|}
\hline \multirow[b]{2}{*}{ Income level } & \multicolumn{6}{|c|}{ Affordability Index Range } \\
\hline & Unserved & $\leq 5.0$ & $5.1-7.0$ & $7.1-10.0$ & $10.1-16.0$ & $>16.0$ \\
\hline High & $\begin{array}{l}2463 \\
(11.4 \%)\end{array}$ & $\begin{array}{l}327 \\
(1.5 \%)\end{array}$ & $\begin{array}{l}5406 \\
(25.0 \%)\end{array}$ & $\begin{array}{l}9978 \\
(46.2 \%)\end{array}$ & $\begin{array}{l}3415 \\
(15.8 \%)\end{array}$ & $\begin{array}{l}21 \\
(0.1 \%)\end{array}$ \\
\hline Middle & $\begin{array}{l}2106 \\
(8.2 \%)\end{array}$ & $\begin{array}{l}1068 \\
(4.1 \%)\end{array}$ & $\begin{array}{l}1792 \\
(7.0 \%)\end{array}$ & $\begin{array}{l}7066 \\
(27.4 \%)\end{array}$ & $\begin{array}{l}13,153 \\
(51.1 \%)\end{array}$ & $\begin{array}{l}564 \\
(2.2 \%)\end{array}$ \\
\hline Moderate & $792(5.5 \%)$ & $10(0.1 \%)$ & $704(4.9 \%)$ & $2030(14.2 \%)$ & $3386(23.7 \%)$ & $7356(51.5 \%)$ \\
\hline Low & $\begin{array}{l}658 \\
(19.2 \%)\end{array}$ & $\begin{array}{l}3 \\
(0.1 \%)\end{array}$ & $\begin{array}{l}3 \\
(0.1 \%)\end{array}$ & $\begin{array}{l}2 \\
(0.1 \%)\end{array}$ & $\begin{array}{l}941 \\
(27.5 \%)\end{array}$ & $\begin{array}{l}1821 \\
(53.1 \%)\end{array}$ \\
\hline Total & 6019 & 1408 & 7905 & 19,076 & 20,895 & 9762 \\
\hline$\%$ of All Children & $9.3 \%$ & $2.2 \%$ & $12.1 \%$ & $29.3 \%$ & $32.1 \%$ & $15.0 \%$ \\
\hline
\end{tabular}

Note. Numbers within parentheses are row percentages 
maximizes its usefulness for community planning, advocacy, and resource allocation. Using GIS methods and publicly available data, our affordability index has the advantage of taking into account (a) cost in relation to family income, (b) supply and demand by weighting ECE seats by both price point and the number of children potentially competing for these seats, and (c) situation of services within a 3-mile driving radius of a family's home.

Results for this study were consistent with what is reported for the U.S. overall: ECE programs are not affordable, and there is considerable inequity in affordability (Child Care Aware of America 2018). On average, families in Honolulu County would expect to pay about $9 \%$ of their income to purchase ECE services for a single child; however, the affordability index varied widely around this mean, indicating that some families have a much higher payment burden. More important, only $14 \%$ of children had access to ECE that met the affordability criterion of $7 \%$ or less of total family income. In addition, $9 \%$ of children lived in ECE deserts, with no access to any nearby program. Affordability was clearly related to median neighborhood income, with the relative cost of ECE (the affordability index) being over twice as high in low-income vs. highincome neighborhoods. Despite the relatively better affordability in wealthier neighborhoods, the majority of children, even in middle- and high-income neighborhoods, did not have access to affordable ECE. While the lowest-income families may be eligible for tuition subsidies or no-cost programs, most U.S. working class and middleincome families have no such sources of public assistance.

Visualization of affordability at the level of both residential lots and neighborhood clusters provided an easily understood view of where the need for affordable ECE seats was greatest. In particular, the hot spot analysis identified areas where ECE was significantly less affordable than average. These areas would be of high priority for expanding the number of seats and/or increasing the availability of subsidized, no-cost, or sliding fee programs. Of policy interest is the fact that the poorest areas were not always the least well-served, reflecting the availability of no-cost and low-cost programs restricted to economically disadvantaged families. The hot spot analysis could also be used to identify gap-group areas, namely moderate- and middle-income neighborhoods with a shortage of affordable ECE seats.

A key advantage of our approach was the use of distance-based or family-focused measurement. Distance-based measures are both more accurate and more continuous than those based on availability inside a static area such as ZIP code or county. Areabased measures ignore the fact that families may select ECE seats outside of these boundaries and that these seats may be located closer to home than some seats inside the target area. Distance-based measures are also more continuous, without an abrupt change in value at each boundary. Our study was unusual in using residential housing lot data to estimate family location. Many floating catchment area studies use more macro-level data such as the centroids of zipcodes, census tracts or census blocks to estimate population location (Mao and Nekorchuk 2013; Zhang et al. 2011). Using macro-level data for distance-based measures is less effective and sensitive, especially when short distances are involved. We computed the affordability index at a very micro-grained level, as was needed to make conclusions about neighborhoods.

Policymakers have noted the usefulness of GIS approaches and have urged that they be applied more often to early childhood issues (Lin and Madill 2019). Currently, few such examples exist in the published research literature. Kawabata (2015) documented 
much micro-level variability in the supply-to-demand ratio of childcare in Tokyo neighborhoods. van Ham and Mulder (2005) found that spatial access to childcare affects maternal employment; mothers are more likely to work when there is a higher per capita number of childcare seats within a 10-min driving radius. In the most sophisticated GIS-based study to date, Davis et al. (2019) calculated adjusted supply, driving time, cost, and quality of ECE services within a 20-min drive from the estimated location of children's homes. They found driving times to be shorter, and both price and quality to be higher in the urban capital compared to the rest of their state. There was a complex relationship between the dimensions of accessibility and family ethnicity. Perhaps because of Minnesota's public preK and voucher programs, families living below the poverty line had the best overall access including supply, travel time, prices, and program quality. This stands in contrast to our finding that lower-income neighborhoods had the worse affordability scores. This difference is likely accounted for by respective state policy: Minnesota serves a much higher percentage of children in public preK than does Hawai'i (Friedman-Krauss et al. 2020). The two studies also differed in terms of how family locations were estimated and income levels were defined.

The methods used in our study are flexible and can be adjusted to address different questions relating to policy or community advocacy. Our micro focus on residential lots and lot clusters makes it easy to identify underserved neighborhoods and would be especially useful for purposes such as grassroots advocacy for neighborhood services, decisions on where to locate new public ECE classrooms, or informing entrepreneurial providers of the best places to consider opening a new family childcare business or private childcare center. We selected a 3-mile distance, suitable for our dense urban population and unique mountainous terrain that often makes seemingly adjacent areas inaccessible. Longer distances would be better suited when focusing on rural locales or large geographic areas and shorter distances may be useful in densly populated areas where walking to childcare is feasible. We also chose to base distance on driving in a private car. Public transit data could be used to determine the number of seats accessible by mass transit; doing so may reveal large differences in accessibility if rural areas have less transit coverage. Our lot-level index could also be aggregated at higher levels, such as the census tract, school or legislative district, municipality, or county. A city-level analysis, for example, would be useful for identifying inequities and allocating government resources across an entire state.

Depending on what kinds of data are available, distance-based methods can address a wide variety of policy-relevant concerns. For example, with access to the addresses of families receiving childcare subsidies, one could identify low-income areas where few families make use of available benefits and determine whether low uptake may be due to scarcity of available nearby seats. One could also look at the supply or affordability of different kinds of ECE, such as infant-toddler care, private vs. public preschool, or programs offering nontraditional hours.

Our method had several limitations. The first of which is that in most cases, researchers do not have access to family-level data such as families' actual residential addresses, income, or enrollment of young children in specific ECE programs. As is the case in other distance-based studies, we made assumptions about the characteristics of hypothetical families: we assumed that young children were evenly distributed across housing units and assigned the same estimated family income to all housing units 
within a census tract. Second, we were not able to adjust for priority demographics, i.e., eligibility criterion for program entry. Not all children are eligble to enroll in all ECE programs. In the U.S., Head Start and Early Head Start have means-tested eligibility and primarily serve children living in poverty. And some ECE programs have competitive admission - private schools may require children to pass an entrance examination or interview. Ideally, given more detailed information about child and family characteristics, one could adjust for differential eligibility. Third, our analysis was also limited to the distance between the home and the ECE provider. Families may prefer to use ECE services close to their place of work or near the home of a grandparent who picks up the child from school. Fourth, because we had no access to enrollment or benefit data, affordability was based on a percentage of estimated income, ignoring the fact that some low-income families receive subsidies or scholarships. We did, however, take in to account the number of seats in no-cost programs like Head Start. Finally, we also assumed that all families want access to ECE services, possibly over-estimating demand.

In conclusion, access to affordable ECE programs is a key component of child and family well-being, with wider implications for the overall community. Tracking the availability and equitable distribution of this resource, therefore, is important for promoting the well-being of communities and their members. Our ECE affordability index is useful for early childhood advocates, community leaders, and policymakers. The social indicator approach, i.e., selecting and monitoring key quantifiable indicators of community well-being, allows for comparisons across time, communities, and demographic sub-groups. Mapping is an effective way to visualize and communicate information about resource distribution across neighborhoods, communities, and municipalities. The methods used in this study are applicable to a wide range of resource access issues and may serve as a model to those working in other areas of community well-being.

Open Access This article is licensed under a Creative Commons Attribution 4.0 International License, which permits use, sharing, adaptation, distribution and reproduction in any medium or format, as long as you give appropriate credit to the original author(s) and the source, provide a link to the Creative Commons licence, and indicate if changes were made. The images or other third party material in this article are included in the article's Creative Commons licence, unless indicated otherwise in a credit line to the material. If material is not included in the article's Creative Commons licence and your intended use is not permitted by statutory regulation or exceeds the permitted use, you will need to obtain permission directly from the copyright holder. To view a copy of this licence, visit http://creativecommons.org/licenses/by/4.0/.

\section{References}

Acevedo-Garcia, D., Hardy, E., Reece, J., \& Gambhir, S. (2011). Equity in early opportunities to learn: Examining the roles of place, space, and race-exploratory spatial analysis of the density of high-quality early learning centers, neighborhood opportunity and racial composition in Ohio and Massachusetts. Paper prepared for the Federal Reserve Bank of Cleveland 2011 Policy Summit. http://kirwaninstitute. osu.edu/my-product/equity-in-early-learning-opportunities-examining-the-roles-of-place-space-and-race/. Accessed 4 Aug 2020.

Acevedo-Garcia, D., Noelke, C., McArdle, N., Sofer, N., Huntington, N., Hardy, E., Huber, R., Baek, M., \& Reece, J. (2020). The geography of child opportunity: Why neighborhoods matter for equity. First findings from the Child Opportunity Index 2.0. Waltham, MA: Brandeis University, Heller School for 
Social Policy and Management. http://diversitydatakids.org/research-library/research-report/geographychild-opportunity-why-neighborhoods-matter-equity. Accessed 4 Aug 2020.

Anderson, B., \& Geldenhuys, D. J. (2011). The relationship between absenteeism and employer-sponsored child care. South African Business Review, 15(3), 21-45.

Barnett, W. S. (2011). Effectiveness of early educational intervention. Science, 333, 975-978.

Belfield, C. R. (2018). The economic impacts of insufficient child care on working families. New York: Council for a Strong America https://www.strongnation.org/articles/780-want-to-grow-the-economy-fixthe-child-care-crisis. .

Ben-Arieh, A. (2008). The child indicators movement: Past, present, and future. Child Indicators Research, 1(1), 3-16.

Ben-Arieh, A. (2010). Developing indicators for child well being in a changing context. In C. McAuley \& W. Rose (Eds.), Child well-being: Understanding children's lives (pp. 129-142). London: Jessica Kingsley Publishers.

Bright Horizons Family Solutions. (2013). The lasting impact of employer-sponsored child care centers. Watertown, MA: Author. https://www.brighthorizons.com/ / media/ baaef6571dc04ae4802d735ec39b6745.pdf. Accessed 4 Aug 2020.

Bureau of Labor Statistics, U.S. Department of Labor. (2019). Employment characteristics of families-2018. Economic News Release. Washington DC, Author. https://www.bls.gov/news.release/pdf/famee.pdf. Accessed 4 Aug 2020.

Chien, N. (2019). Factsheet: Estimates of child care eligibility \& receipt for fiscal year 2015. Washington, DC: Office of the Assistant Secretary for Planning \& Evaluation, U. S. Department of Health \& Human Services https://aspe.hhs.gov/system/files/pdf/260361/CY2015ChildCareSubsidyEligibility.pdf.

Child Care Aware of America. (2018). The U.S. and the high cost of child care: A review of prices and proposed solutions for a broken system. Alexandria VA: Author.

Community Reinvestment Act (Regulation BB). (2002). 12 CFR § 228.12.

Council of Economic Advisors. (2015). The economics of early childhood investments. Washington, DC: Author.

Davis, E., Lee, W. F., \& Sojourner, A. (2019). Family-centered measures of access to early childhood care and education. Early Childhood Research Quarterly, 47, 472-486.

DeBaryshe, B. D., Bird, O., Stern, I., \& Zysman, D. (2017). Hawai i early learning needs assessment. Honolulu: University of Hawai'i Center on the family. https://uhfamily.hawaii.edu/sites/uhfamily.hawaii. edu/files/publications/HIEarlyLearningNeeds_2017.pdf.

Eurofound. (2012). Third European quality of life survey-Quality of life in Europe: Impacts of the crisis. Luxembourg: Publications Office of the European Union.

European Commission. (2014). Employment and social developments in Europe 2013. Brussels: European Commission Directorate-General for Employment, Social Affairs and Inclusion.

European Commission/EACEA/Eurydice. (2019). Key data on early childhood education and care in Europe - 2019 edition. In Eurydice report. Luxembourg: Publications Office of the European Union.

Friedman, D. E. (2001). Employer supports for parents with young children. The Future of Children, 11(1), $62-77$.

Friese, S., Lin, V., Forry, N., \& Tout, K. (2017). Defining and measuring access to high quality early care and education: A guidebook for policymakers and researchers. OPRE report \#2017-08. Washington, DC: Office of Planning, research and evaluation, Administration for Children and Families, U.S. Department of Health and Human Services.

Friedman-Krauss, A. H., Barnett, W. S., Garver, K. A., Hodges, K. S., Weisenfeld, G. G., \& Gardiner, B. A. (2020). The state of preschool 2019: State preschool yearbook. New Brunswick, NJ: National Institute for Early Education Research.

Forry, N., Tout, K., Rothenberg, L., Sandstrom, H., \& Vesely, C. (2013). Child care decision-making literature review. OPRE brief 2013-45. Washington DC: Office of Planning, research and evaluation, Administration for Children and Families, U.S. Department of Health and Human Services.

Gammage, S., Sultana, N., \& Kes, A. (2019). Maximizing competitiveness: Firms the help workers balance care and work reap rewards. Washington, DC: International Center for Research on Women.

Glass, J. L., \& Estes, S. B. (1997). The family responsive workplace. Annual Review of Sociology, 23(1), 289313.

Gormley, J., Phillips, D., \& Gayer, T. (2008). Preschool programs can boost school readiness. Science, 320, 1723-1724.

Guagliardo, M. F. (2004). Spatial accessibility of primary care: Concept, methods and challenges. International Journal of Health Geographics, 3, 3-13. 
Hanna-Attisha, M., LaChance, J., Sadler, R. C., \& Schnepp, A. C. (2016). Elevated blood lead levels in children associated with the Flint drinking water crisis: A spatial analysis of risk and public health response. American Journal of Public Health, 106(2), 283-290.

Kawabata, M. (2015). Childcare access and employment: The case of women with preschool-aged children in Tokyo. Review of Urban \& Regional Development Studies, 26(1), 40-56.

Karoly, L. A. (2016). The economic returns to early childhood education. The Future of Children, 26(2), 3756.

Lauber, V., \& Storck, J. (2016). Helping with the kids? How family-friendly workplaces help parental wellbeing and behavior. Berlin: German Institute for Economic Research.

Lee, Y., \& Hong, J. H. (2011). Does family-friendly policy matter? Testing its impact on turnover and performance. Public Administration Review, 71, 870-879.

Li, M. T., Yang, L. B., \& Wei, Y. (2016). Improved Gaussian based 2-step floating catchment area method: A case study of green space accessibility in Shanghai. Progress in Geography, 35(8), 990-996.

Lin, V., \& Madill, R. (2019). Incorporating spatial analyses into early care and education research. OPRE research brief \#2019-88. Washington, DC: Office of Planning, research, and evaluation, Administration for Children and Families, U.S. Department of Health and Human Services.

Lippman, L. H. (2006). Indicators and indices of child well-being: A brief American history. Social Indicators Research, 83, 39-53.

Luo, W., \& Wang, F. (2003). Measures of spatial accessibility to health care in a GIS environment: Synthesis and a case study in the Chicago region. Environment and Planning B: Planning and Design, 30, 865-884.

Macdonald, D. (2018). Child care deserts in Canada. Ottawa, ON: Canadian Centre for Policy Alternatives.

Magnuson, K. A., Meyers, M, K., Ruhm, C.J., \& Waldfogel, J. (2004). Inequality in preschool education and school readiness. American Education Research Journal, 41, 115-157.

Malik, R. (2018). The effects of universal preschool in Washington, DC: Children's learning and mothers' earnings. Washington, DC: Center for American Progress.

Malik, R., Hamm, K., Schochet, L., Novoa, C., Workman, S., \& Jessen-Howard, S. (2018). America's child care deserts in 2018. Washington DC: Center for American Progress.

Mao, L., \& Nekorchuk, D. (2013). Measuring spatial accessibility to healthcare for populations with multiple transportation modes. Health \& Place, 24, 115-122.

Mathur, A., \& McCloskey, A. (2014). How to improve economic opportunity for women. Washington, DC: American Enterprise Institute. https:/www.aei.org/research-products/report/how-to-improve-economicopportunity-for-women/. Accessed 4 Aug 2020.

Morrissey, T. W. (2017). Child care and parent labor force participation: A review of the research literature. Review of Economics of the Household, 15, 1-24.

National Scientific Council on the Developing Child. (2007). The timing and quality of early experiences combine to shape brain architecture: Working paper No. 5. https://developingchild.harvard.edu/wpcontent/uploads/2007/05/Timing_Quality_Early_Experiences-1.pdf. Accessed 4 Aug 2020.

National Survey of Early Care and Education Project Team. (2016). Fact Sheet: How Far Are Early Care and Education Arrangements from Children's Homes? OPRE Report No. 2016-10. Washington, D.C.: Office of Planning, Research and Evaluation, Administration for Children and Families, U.S. Department of Health and Human Services.

OECD. (2019). Education at a glance 2019: OECD indicators. Paris: OECD Publishing.

OECD. (n.d.a). OECD Family Database. Indicator LMF1.2 maternal employment. (2014 data, updated 26-092016). http://www.oecd.org/social/family/database.htm. Accessed 3 Aug 2020.

OECD. (n.d.b). OECD.Stat. Net childcare costs for parents using childcare, including housing benefits. (2019 data). https://stats.oecd.org/. Accessed 3 Aug 2020.

OECD. (n.d.c). OECD Family Database. Indicator PF3.2 enrollment in childcare and preschool. (2017 data, updated 05-11-2019). http://www.oecd.org/social/family/database.htm. Accessed 3 Aug 2020.

Philips, D., Lipsey, M., Dodge, K., Haskins, R., Bassok, D., Burchinal, M., Duncan, G., Dynarski, M., Magnusson, K., \& Welland, C. (2017). The current state of scientific knowledge on pre-kindergarten effects. Washington DC: Brookings Institution.

Pfeiffer, D. U., Robinson, T. P., Stevenson, M., Stevens, K. B., Rogers, D. J., \& Clements, A. C. A. (2008). Spatial analysis in epidemiology. Oxford: Oxford University Press.

Rushton, G. (2003). Public health, GIS, and spatial analytic tools. Annual Review of Public Health, 24, 43-56.

Schmit, S., \& Walker, C, (2016). Disparate access: Heads Start and CCBDG data by race and ethnicity. Washington DC: CLASPe. https:/www.clasp.org/publications/report/brief/disparate-access-head-startand-ccdbg-data-race-and-ethnicity. Accessed 4 Aug 2020. 
Shellenback, K. (2004). Child care and parent productivity: Making the business case. Ithaca, NY: Cornell University. http://s3.amazonaws.com/mildredwarner.org/attachments/000/000/074/original/15421008542.pdf. Accessed 4 Aug 2020.

SmartParcels. (2017). Parcel Data. https:/www.digSMart.com/platform/smartparcels/ Digital Map Products, 5201 California Avenue, Suite 200 Irvine, CA, 92617. https://www.digmap.com/platform/smartparcels/. Accessed 4 Aug 2020.

Sandstrom, H., Claessens, A., Stoll, M., Greenberg, E., Alexander, D., Runes, C., \& Henly, J. R. (2018). Mapping child care demand and the supply of care for subsidized families. Washington DC: Urban Institute. Retrieved from https://www.urban.org/research/publication/mapping-child-care-demand-andsupply-care-subsidized-families .

The Front Project. (2019). A smart investment for a smarter Australia: Economic analysis of universal early childhood education in the year before school in Australia. https:/www.thefrontproject.org.au/images/ downloads/ECO\%20ANALYSIS\%20Full\%20Report.pdf. Accessed 4 Aug 2020.

U.S. Census Bureau. (2017a). American Community Survey 5-year estimates, Table B01003: Total population. https://data.census.gov/. Accessed 1 Feb 2020.

U.S. Census Bureau. (2017b). American Community Survey 5-year estimates, Table B23008: Age of own children under 18 years in families and subfamilies by living arrangements by employment status of parents. https://data.census.gov/. Accessed 1 Feb 2020.

U.S. Census Bureau. (2017c). American Community Survey 5-year estimates, Table B19125: Median family income in the past 12 months (in 2016 inflation-adjusted dollars) by presence of own children under 18 years. https://data.census.gov/. Accessed 1 Feb 2020.

U.S. Department of Health and Human Services, Office of Child Care. (2016). Child Care and Development Fund (CCDF): Final rule. Washington, D.C.: Author.https:/www.federalregister.gov/documents/2016/ 09/30/2016-22986/child-careand-development-fund-ccdf-program. Accessed 1 Feb 2020.

van Ham, M., \& Mulder, C. H. (2005). Geographical access to childcare and mothers' labour-force participation. Journal of Economic and Social Geography, 96, 63-74 https://doi.org/10.1111/j.1467-9663.2005. 00439.x.

Yoshikawa, H., Weiland, C., \& Brooks-Gunn, J. (2016) When does preschool matter? The Future of Children, 26(2), 21-35.

Zhang, X., Lu, H. \& Holt, J.B. (2011). Modeling spatial accessibility to parks: A national study. International Journal of Health Geographics, 10, 31.

Publisher's Note Springer Nature remains neutral with regard to jurisdictional claims in published maps and institutional affiliations. 